\title{
ИЗУЧЕНИЕ ЭФФЕКТИВНОСТИ КОМБИНАЦИИ МИНЕРАЛСОДЕРЖАЩИХ ЛЕКАРСТВЕННЫХ ПРЕПАРАТОВ НА ОСНОВЕ БИШОФИТ И МОЛЕКУЛ ТИТАНА ПРИ ЛЕЧЕНИИ ВОСПАЛИТЕЛЬНЫХ ЗАБОЛЕВАНИЙ ПАРОДОНТА
}

\section{STUDY OF THE EFFECTIVENESS OF A COMBINATION OF MINERAL-CONTAINING DRUGS BASED ON BISCHOFITE AND TITANIUM MOLECULES IN THE TREATMENT OF INFLAMMATORY PERIODONTAL DISEASES}

\section{N. Sharonova \\ E. Temkin}

Summary: Periodontal diseases occupy a leading place among the pathologies of the oral cavity in prevalence.

Periodontal pockets are the main depot of pathogenic microflora, which is the main etiological factor in the emergence and progression of periodontitis. Periodontitis is characterized by inflammatory and destructive processes leading to the formation of foci of chronic infection in the oral cavity, violation of occlusive-articulatory relationships of dentition, sensitization of the body, the occurrence of cross-allergic reactions, reduced reactivity of the body as a whole.

High prevalence of periodontitis in persons suffering from diabetes mellitus, obesity, cardiovascular diseases, pathology of the gastrointestinal tract, endocrine and other diseases was revealed. Foreign scientists noted that odontogenic infection is one of the main factors of somatic pathology. This effect is due to hetero-and autogenous persistence, depressing the impact of chronic sepsis foci on the immune system.

The research work on the microbiological efficacy of a combination of mineral-containing medicinal preparations based on bischofite and titanium molecules was carried out in comparison with the standard method of treatment of periodontal inflammatory diseases.

To date, the development of new drugs for the treatment of inflammatory periodontal diseases is an urgent issue.

Keywords: periodontitis, bischofite, Tizol, parodontopathogenic microorganisms.

\author{
Шаронова Наталья Александровна \\ Врач стоматолог-терапевт, ГАУЗ СП №9 \\ kryuchkova.n90@mail.ru
}

Темкин Эдуард Семенович

Д.м.н., профессор, ФГБОУ ВО ВолгГМУ Минздрава России

Аннотация: Заболевания пародонта занимают одно из лидирующих мест по распространенности среди патологий полости рта.

Пародонтальные карманы являются основным депо патогенной микрофлоры, которая и является главным этиологическим фактором возникновения и прогрессирования пародонтитов. Пародонтит характеризуется воспалительно-деструктивными процессами, ведущие к образованию очагов хронической инфекции в полости рта, нарушению окклюзионно-артикуляционных взаимоотношений зубных рядов, сенсибилизации организма, возникновению перекрестной аллергической реакции, снижению реактивности организма в целом.

Выявлено высокое распространение пародонтитов у лиц страдающих сахарным диабетом, ожирением, сердечно-сосудистыми заболеваниями, патологиями желудочно-кишечного тракта, эндокринными и другими заболеваниями. Зарубежными учеными отмечено, что одонтогенная инфекция является одним из главных факторов появления соматической патологии. Такое воздействие оказывается за счет гетеро- и аутогенной персистенции, угнетающего воздействия очагов хрониосепсиса на иммунную систему. Проведена исследовательская работа по изучению эффективности комбинации минералсодержащих лекарственных препаратов на основе бишофит и молекул титана в сравнении со стандартной методикой лечения воспалительных заболеваний пародонта.

До настоящего времени является актуальным вопрос разработки новых лекарственных препаратов для лечения воспалительных заболеваний пародонта.

Ключевые слова: пародонтит, бишофит, Тизоль, пародонтопатогеные микроорганизмы. ародонтит - воспалительно-деструктивное заболевание, полигенного характера с иммунно-регуляторными расстройствами. Заболевания пародонта занимают лидирующее место среди патологий полости рта, по распространенности, находясь на втором месте после кариеса [1]. Люди, имеющие данный недуг, рано теряют зубы, что приводит к нарушению акта жевания и работы височно-нижнечелюстного сустава, появлению эстетического недостатка и в целом социальной дезадаптации [2].

Все это сводит данную патологию к социально-значимым болезням, которые могут оказывать влияние на качество и продолжительность жизни индивидуума. 
Данная патология имеет значительное распространение среди населения, а в последнее время отмечается прогрессирование у лиц молодого возраста. Заболевания пародонта встречаются практически у всех лиц старше 40 лет (эксперты ВО3, 2006), в том числе в промышленно развитых странах у 90\% выявляются более или менее выраженные клинические признаки гингивита, у $50 \%$ и у $3 \%$ - симптомы пародонтита средней и тяжелой степени [3]. Так же по ряду исследований распространение воспалительных заболеваний пародонта среди людей разных возрастных групп приближается к 100 \% $[4,5]$.

В современной стоматологии существует ряд научно подтвержденных концепций о взаимодействии экосистемы полости рта, гигиенических навыков человека, уровня иммунологической резистентности тканей пародонта и организма в целом, особенностей окружающей среды, поведенческих характеристик человека и его генетических особенностей [6].

Одним из важнейших показателей состояния организма в целом и полости рта - является микрофлора [7]. Многие исследователи доказали, что микробный фактор играет ведущую роль в патогенезе воспалительных заболеваний пародонта [8]. Данная патология возникает после нарушения равновесия среди резидентных видов определенного микробиоценоза под воздействие внешних и системных внутренних факторов, а также под влиянием изменения иммунной и эндокринной систем. Почти всегда при этих заболеваниях наблюдается сенсибилизация организма к представителям нормальной микрофлоры полости рта, к продуктам их жизнедеятельности.

Итогом воспалительных заболеваний пародонта является разрушение альвеолярной кости с образованием пародонтальных карманов, служащих резервуаром для патогенных микроорганизмов, продуктов их жизнедеятельности и медиаторов воспаления, воздействующих не только местно, но и на организм в целом. В здоровой зубодесневой борозде в основном находятся факультативные грамположительные бактерии. По мере прогрессирования воспалительного процесса в тканях пародонта преобладающими видами микроорганизмов становятся строгие анаэробы, особенно так называемые пародонтопатогенные микроорганизмы: Porphyromonas gingivalis, Prevotella intermedia, Treponema denticola, Bacteroides forsythus, Actinobacillus actinomycetemcomitans и др. Данные представители одновременно с анаэробным типом дыхания отличаются высокими адгезивными, инвазивными и токсическими свойствами по отношению к тканям пародонта. Для облегчения метаболического взаимодействия микроорганизмы объединяются в биопленку, структура которой повышает их устойчивость ко всем раздражителям $[9,10]$.

На сегодняшний день существует большой арсенал методов лечения пародонтопатологий, однако одни не приносят положительного результата, другие дорогостоящие и не всегда доступны большинству пациентам. Неэффективность проведенного лечения возможно связать с отсутствием крепкой мотивации (больные начинают лечение, не получив быстро эффекта ко второму посещению не приходят на последующие), безграмотностью пациентов в вопросе заболеваний пародонта и отсутствием информирования врачами-стоматологами-терапевтами (как следствие позднее обращение за квалифицированной помощью), набирающей популярность среди населения натуропатией. Данное направление является альтернативом традиционной медицины, где лечение проводится за счет применения только естественных лекарственных средств природного происхождения. Что уже вызывает сложности в проведении терапии, так как традиционная схема включает использование препаратов химического происхождения: метронидазола, являющегося «золотым стандартом»; антибактериальных; антисептических; нестеройдных и др.

К сожалению, медикаментозная терапия в особенности антибактериальная наряду с положительными свойствами может оказывать негативное влияние, такое как токсическое действие, способствовать развитию дисбактериоза (дисбиоза), возникновению аллергических реакций, эндотоксического шока (с временным ухудшением состояния пациента), отрицательному взаимодействию с другими препаратами и формированию антибиотикорезистентности.

В соответствии с вышесказанным на пародонтологическомприеме следуетуделять внимание кналаживанию доверительных отношений в системе «врач-пациент», грамотному, тактичному и полному предоставлению информации о патологии пациента, формированию у больного положительных мотивов к лечению.

Не менее актуальным остается вопрос поиска и разработки новых препаратов, исключающих негативное влияние и одновременно обладающих полифункциональным характером воздействия.

Выходом является совместное применение со стандартной методикой лечения заболеваний пародонта комбинированного природного минералсодержащего лекарственного препарата на основе геля «Поликатан» и аквакомплекса титана глицеросольвата «Тизоль».

Разработанный учеными Волгоградского государственного медицинского университета магнийсодержащий гель «Поликатан» (ВФС 42-2952-97, регистраци- 
онное удостоверение №98/133/15, дата регистрации 23 апреля 1998г.) был создан на основе природного бишофита [11]. Большое количество исследований показали отсутствие у бишофита канцерогенных и аллергизирующих свойств, а так же низкую токсичность [12]. В Волгоградской области имеются большие скопления минерала бишофит. Широкое использование в лечебной деятельности данного препарата основывается на его широком спектре оказываемых эффектов (противовоспалительном, антисептическом, сосудорасширяющим, гиполипидемическим, иммунотропным и фунгистатическом действии) [13]. «Поликатан» усиливает фагоцитарную активность нейтрофилов, содержит в своем составе большое количества магния, который оказывает влияние на все фазы воспаления (альтерацию, экссудацию и пролиферацию), играет большую роль в стабилизации иммунореактивности слизистой оболочки полости рта. Также стоит отметить высокий некролитический и ранозаживляющий эффект производных бишофита на инфицированные очаги [14]. Усиление процесса регенерации происходит путем коррекции энергетического обмена в восстанавливающейся ткани [15].

В свою очередь «Тизоль ${ }^{\circledR}$ » - аквакомплекс титана глицеросольвата (Регистрационный номер P N 001667/012002. Одобрено Фармакологическим комитетом Минздрава России 5 июня 2003г. Протокол N 5п) был разработан Организацией лабораторных исследований медицинских препаратов (ООО «Олимп», г. Екатеринбург) [16]. В состав данного препарата входят молекулы титана, участвующие в нормальном функционировании организма (построение эпителиальной ткани, поддержание процессов иммуногенеза и эритропоэза, участие в восстановлении целостности костей) [16]. «Тизоль ${ }^{{ }}$》 является металлокомплексным соединением, обладает противовоспалительным, бактерицидным, регенерирующим, антивирусным, антиаллергическим, антиоксидантным, анальгезирующим действием, образовывает крепкие водородные связи с другими лекарственными веществами. «Тизоль ${ }^{\circledR}$ » предохраняет от высыхания и отека ткани, усиливает их оксигенацию. Данный препарат является на сегодняшний день самым сильным транскутанным проводником [16].

Комбинированное применение данных препаратов способствует суммированию отдельных фармакологических эффектов и их усилению.

Включение аквакомплекса титана глицеросольвата «Тизоль ${ }^{\circledR}$ в схему лечения позволяет обеспечить стойкость и стабильность «Поликатана», депонирование препарата и пролонгированное его воздействие, а также более глубокое проникновение к очагу воспаления.

Данная комбинация соответствует требованиям GMP и отвечает требованиям национальной фармакопии [17]. По результатам исследования, по разработке технологии стоматологического геля с учётом требований, изложенных в ICHQ8 «Фармацевтическая разработка» и ICHQ9 «Управление рисками для качества», данный стоматологический гель обладает удовлетворительными технологическими и биофармацевтическими свойствами [17].

\section{Шель исследования}

Оценить эффективность применения комбинации минералсодержащих лекарственных препаратов на основе бишофита и аквакомплекса титана глицеросольвата со стандартной методикой лечения воспалительных заболеваний пародонта.

\section{Материалы и методы исследования}

Под наблюдением находилось 62 человека в возрасте от 21 до 60 лет, с диагнозом хронический генерализованный пародонтит средней степени тяжести. Результаты проводимой терапии оценивались в динамике на 3 и 7 день после начала лечения по следующим критериям: индекс гигиены (ИГ) по GreenVermillion (1960), папиллярно - маргинально - альвеолярный индекс (РМА) по Parma. С. (1960), индекс Muhlemann (1971) и бактериологический посев.

Бактериологическое исследование проводилось до и после лечения, на 7 день.

Исследование проводилось на базе Научно-исследовательского Противочумного института Роспотребнадзора города Волгограда. Забор биоматериала проводился на терапевтическом приеме, непосредственно врачом-терапевтом, из пародонтального кармана стерильным зондом, исключая соприкосновения инструмента с другими поверхностями слизистой оболочки полости рта и поверхностей зубов. Далее материал помещался в гелевую транспортную систему со средой Эймса в полимерную пробирку, которую доставляли в лабораторию в течение 24 часов, где материал засевался на различные питательные среды и инкубировался до выделения отдельных микроорганизмов.

Пациенты были разделены на две группы (основная и сравнительная) по 31 человеку, в зависимости от метода лечения.

Всем пациентам проводилась профессиональная гигиена полости рта с последующим обучением и контролем. Подбирались индивидуальные средства гигиены, а также давались рекомендации по рациональному питанию. По показаниям, пациентам проводился закрытый кюретаж, при помощи специальных кюрет, в целом са- 
Динамика индексных показателей у пациентов, пролеченных комбинацией геля «Поликатан и Тизоль» и препаратом на основе метронидазол.

\begin{tabular}{|l|c|c|c|c|c|c|}
\hline & \multicolumn{2}{|c|}{ До лечения } & \multicolumn{2}{c|}{ На 3 день } & \multicolumn{2}{c|}{ На 7 день } \\
\hline & 1 группа & 2 группа & 1 группа & 2 группа & 1 группа & 2 группа \\
\hline ИГ по GreenVermillion (1960) & $3,8 \pm 0,2$ & $3,9 \pm 0,2$ & $2,5 \pm 0,1$ & $2,9 \pm 0,1$ & $0,8 \pm 0,06$ & $1,1 \pm 0,08$ \\
\hline Индекс Muhlemann & $1,78 \pm 0,02$ & $1,8 \pm 0,02$ & $1,09 \pm 0,03$ & $1,2 \pm 0,03$ & $0,3 \pm 0,03$ & $0,4 \pm 0,03$ \\
\hline PМА по Parma. С. (1960) & $49 \pm 0,9$ & $49 \pm 0,85$ & $33 \pm 1,02$ & $35 \pm 0,95$ & $13 \pm 1,3$ & $17 \pm 0,9$ \\
\hline
\end{tabular}

нация полости рта. После медикаментозной обработки удалялись над- и поддесневые зубные отложения ультразвуковыми аппаратами в комбинации с аэрофлоу, с наложением противовоспалительных препаратов.

В основной группе местно применяли гель «Поликатан и Тизоль» В виде 15-минутных аппликаций на десну, в сравнительной группе на десну накладывали лечебные повязки с препаратами на основе метронидазола.

Полученные данные индексных показателей обрабатывали в программе Microsoft Office Excel 2013, для большей точности и эффективности обработки статистических данных, с определением средней величины, средней ошибки и оценки достоверности различия независимых групп. Данные считали достоверными при $p<0.05$.

\section{Результаты исследования и их обсужАения}

По данным таблицы 1 в основной группе уровень ИГ снизился на 3 день лечения (на 1,3), на 7 день (на 3). Индекс PMA по Parma. С. (1960) уменьшился на 3 день лечения (на 16), на 7 день (на 36). Индекс Muhlemann стал на 3 день лечения (на 0,7 ниже), на 7 день (на 1,48 ниже).

В сравнительной группе уровень ИГ снизился на 3 день лечения (на 1), на 7 день (на 2,8). Индекс РМА по Parma. С. (1960) уменьшился на 3 день лечения (на 14), на 7 день (на 32). Индекс Muhlemann стал на 3 день лечения (на 0,6 ниже), на 7 день (на 1,4 ниже).

Статистический анализ микробиологического исследования наглядно показывает изменения количественного состава флоры. Среди обследованных пациентов основной группы у 23 человек, что составило 74\%, наблюдалась нормализация микрофлоры у 8 пациентов (26\%) снижение количества микроорганизмов в пародонтальном кармане, пациенты у которых наблюдалось бы отсутствие улучшения, составило 0 (0\%).
Анализ полученных данных в сравнительной группе продемонстрировал у 21 пациента (68\%) наблюдалась нормализация микрофлоры, у 9 (29\%) снижение количества микроорганизмов в пародонтальном кармане, у 1 (3\%) без улучшения.

Данные, полученные в результате клинического исследования позволяют сделать выводы о том, что в основной группе, пролеченной комбинацией гелем «Поликатан» и препаратом аквакомплекса титана глицеросольвата «Тизоль ${ }^{\circledR}$, клиническое улучшение и снятие воспаления наступало у большего количества пациентов на 4-5 сутки, а в сравнительной группе на 7-8 сутки. Также число пациентов с нормализацией микрофлоры пародонтального кармана, уменьшением количества микроорганизмов в пародонтальном кармане составляла больший процент, относительно пациентов пролеченных препаратом с метронидазолом. Эти данные отобразили более эффективное влияние на состав микрофлоры пародонтального кармана комбинации геля «Поликатан и Тизоль».

\section{Выво $\Delta$}

В результате клинического исследования были получены данные, показывающие высокую эффективность и преимущество применения комбинации минералсодержащих лекарственных средств, магнийсодержащего геля «Поликатан» и аквакомплекс титана глицеросольвата «Тизоль ${ }^{\circledR}$ » в комплексном лечении воспалительных заболеваний пародонта. По результатам исследования в кротчайшие сроки наступает устранение признаков воспаления, нормализация трофики тканей, исчезновение неприятных ощущений у пациентов (болезненность, жжение, зуд, кровоточивость, отек десен), а так же улучшение показателей пародонтальных индексов и нормализация микрофлоры в пародонтальных карманах. Что может дать основание рекомендовать применение данной лекарственной комбинации для лечения хронического генеразизованного пародонтита легкой и средней степени тяжести. 


\section{ЛИТЕРАТУРА}

1. Крайнов С.В. Оптимизация лечения хронического генерализованного пародонтита у лиц пожилого возраста: дис. ... канд. мед. наук (14.01.14) / Крайнов Сергей Валерьевич.- Волгоград, 2017.

2. Умалатова Г.Э. Изучение возрастной динамики потери зубов у лиц с заболеваниями пародонта: автореф. дис. . . . канд. мед. наук. - В., 2016. - 25 с

3. Перепечко В.М. Гендерные особенности стоматологического статуса у пациентов с соматической патологией: автореф. дис. ... канд. мед. наук. M., 2011. -24 C.

4. Стрельцов Д.А., Компанцева Е.В. Разработка методик анализа анестезина в мази бишофита с димексидом и анестезином/ Д.А. Стрельцов, Е.В. Компанцева // Разработка, исследование и маркетинг новой фармацевтической продукции: сборник научных трудов (Пятигорская государственная фармацевтическая академия). - Вып. 60. - Пятигорск, 2005. - (.287-288.

5. Шемонаев В.И., Климова Т.Н., Тимачева Т.Б., Саргсян К.А., Мась Е.С., Малышевская Д.В. Системный подход в решении пародонтологичсеких проблем как залог стоматологического здоровья населения / В.И. Шемонаев, Т.Н. Климова, Т.Б. Тимачева, К.А. Саргсян, Е.С. Мась // Волгоградский научно-медицинский журнал. - 2013. - № 3. - С. 52-55.

6. Артюшкевич А.С. Заболевания периодонта. Издательство «медицинская литература», 2006. --- 328 с.

7. Боровский Е.В., Иванов В.С., Максимовский Ю.М. и др. Терапевтическая стоматология. - М., 2001. - 736 с.

8. Матвеева Н.И., Темкин Э.С., Салямов К.Ю., Сысуев Б.Б. Влияние геля Поликатан в комбинации с линкомицином на состояние микрофлоры пародонтальных карманов при лечении воспалительных заболеваний пародонта // Саратовский научно-медицинский журнал. 2011. Т. 7, № 1 (приложение). C. 309-311.

9. Зеленова Е.Г., Закславская М.И., Салина Е.В., Рассанов С.П. Микрофлора полости рта: норма и патология: Учебное пособие. Нижний Новгород: Издательство НГМА, 2004. $-158 \mathrm{c}$.

10. Барер Г.М. Терапевтическая стоматология в 3-х частях: Часть 2: Болезни пародонта: учебник. М.: ГЭОТАР - Медиа, 2008. --- 224 с.

11. Спасов А.А., Мазанова Л.С., Темкин Э.С., Абакумова Т.А., Сысуев Б.Б. Изучение фармакологической активности магнийсодержащего геля «Поликатан» на экспериментальной модели травматического стоматита / А.А. Спасов, Л.С. Мазанова, Э.С. Темкин, Т.А. Абакумова, Б.Б. Сысуев // Вестник Оренбургского государственного университета. Приложение «Биоэлементология». - 2006. - № 12 (62). - С. 240-242.

12. Митрофанова И.Ю., Смирнов А.В., Сысуев Б.Б. Морфологическое исследование репаративных эффектов раствора бишофита и кислоты глицирризиновой на эксперементальной модели полнослойных линейных кожных ран/ И.Ю. Митрофанова, А.В. Смирнов, Б.Б. Сысуев// Волгоградский научно-медицинский журнал. - 2011. - № 4. - С. 10-14.

13. Сысуев Б.Б. Митрофанова И.Ю., Степанова Э.Ф. Перспективы и проблемы создания на основе минерала бишофит эффективных лекарственных форм/ Б.Б. Сысуев, И.Ю. Митрофанова, Э.Ф. Степанова//Фундаментальные исследования. - 2011. - № 6 - С. 218-221.

14. Инновационные лекарственные препараты на основе минерала бишофит глубокой очистки: перспективы и проблемы применения/ И.Ю. Митрофанова [и др.] // Фундаментальные исследования.-2014.-№9.-С.1554-1557.

15. Балабанова Р.М., Федина Т.П. Опыт применения геля тиозь для локальной терапии ревматоидного артрита/ Р.М. Балабанова, Т.П. Федина// Научно-практическая ревматология.-2014.-№3.-С.37-39.

16. Барсукова К.В. Клинико-патогенетическое обоснование применения аквакомплекса титана глицеросольвата (Тизоля) в комплексном лечении больных с переломом нижней челюсти: Автореф. дис. ... канд. мед. наук (14.01.14) / Барсукова Кристина Владимировна.-Воронеж, 2014.- 25 с.

17. Данилина Т.Ф., Ахмедов Н.М., Китаева Т.А., Сысуев Б.Б. Оптимизация адаптации к съемным пластиночным протезам пациентов пожилого возраста/ Т.Ф. Данилина, Н.М. Ахмедов, Т.А. Китаева, Б.Б. Сысуев// Вестник Волгоградского государственного медицинского университета. - 2015.

( ) Шаронова Наталья Александровна (ryuchkova.n90@mail.ru ), Темкин Эдуард Семенович.

Журнал «Современная наука: актуальные проблемы теории и практики» 